International Journal of Economics, Business and Management Research

Vol. 6, No.02; 2022

ISSN: $2456-7760$

\title{
Factors Influencing the Adoption of Software-as-a-services (SAAS): A Gender Perspective
}

\author{
Aminul Haque Russel ${ }^{1}$, Lakkhan Chandra Robidas ${ }^{2}$, Dr. Mohammed Shakhawat Hossain ${ }^{3}$, Dr. \\ Mohamed Emran Hossain ${ }^{4}$ \\ ${ }^{1}$ Daffodil Institute of IT, Department of Business Administration, \\ Dhaka, Bangladesh \\ ${ }^{2}$ Daffodil Institute of IT, Department of Business Administration, \\ Dhaka, Bangladesh \\ ${ }^{3}$ Daffodil Institute of IT, Department of Business Administration, \\ Dhaka, Bangladesh \\ ${ }^{4}$ Daffodil Family, Chief Operating Officer (COO), \\ Dhaka, Bangladesh
}

doi: 10.51505/IJEBMR.2022.6209

URL: http://dx.doi.org/10.51505/IJEBMR.2022.6209

\begin{abstract}
This study investigates the effects of influencing factors (Perceived Ease of Use, Perceived Usefulness and attitudes) on adoption of SaaS, and whether these effects differ between male and female. Data were collected from employees of the different sister concern of Daffodil family, and analyzed using partial least squares - structural equation modeling (PLS-SEM) and MultiGroup Analysis (MGA). The Important-Performance Matrix Analysis (IPMA) was also conducted to gain an insightful understanding of how these factors influence an employee's intention to Adopt SaaS at the gender level. The findings showed that significant differences between male and female employees for the effect of perceived usefulness and attitudes on employee's Adoption intention of Software-as-a-Services (SaaS). Further, there is a significant difference between perceived ease of use and perceived usefulness for both gender groups on SaaS adoption. However, the IPMA results exhibit that the most essential antecedent for both male and female employees' intentions on SaaS is perceived usefulness.
\end{abstract}

Keywords: SaaS, Adoption intention, Gender, PLS-SEM, MGA, IPMA, and TAM.

\section{Introduction}

Software-as-a-Service (SaaS) is an innovative system of providing software applications, based on cloud computing technology and allow organizations to save the expenses of Information Technology (IT) investment on infrastructure, networking, hardware, software and personnel, (Chou \& Chou, 2007). SaaS is primarily used by end users, provides flexible and cost-effective access to information and software through online servers and active collaboration between individual users (Tan \& Kim 2015; Wease et al. 2018). SaaS is multi-tenant software that allows users to access a variety of software items on demand (Benlian \& Hess, 2011). SaaS applications are generally categorized by being easily accessible, feature-rich, and consumer-friendly 


\section{International Journal of Economics, Business and Management Research}

Vol. 6, No.02; 2022

ISSN: $2456-7760$

(Zorrilla \& García-Saiz, 2013). Xin \& Levina, (2008) stated that the maturity of a company's information technology plays a crucial role in adoption of SaaS. According to the Benlian et al., (2009) social influence, attitude toward SaaS-adoption, adoption uncertainty, and strategic value are the most powerful and reliable factors through all types of application. But firm size has no influence on SaaS adoption because previous research suggested that large corporation and small \& medium-sized businesses adopted SaaS at equal rates. Heart, (2010) vendor's reputation and trust are critical for mitigating SaaS risks and encouraging enterprises to embrace it. Benlian, Koufaris, \& Hess, (2011) service quality has a considerably greater influence on satisfaction than perceived usefulness. According to Lee et al. (2013), the most critical barriers for SaaS adoption are consumer and economic reasons, supplier attitude, and the environment.

$\mathrm{Wu}$ (2011) identified the significant influencing variables in adoption of SaaS in individual level by integrating diffusion of innovation theory and technology acceptance model (TAM). The research is limited in telecommunication industry, and may not adequately cover to other industries. From the previous studies, overall cost-saving motivation is insufficient to clarify the decisions to adopt SaaS. Rather, we need to address the behavioral influences of SaaS that are revolutionizing the way people acquire and use software (Klein, Conn, \& Sorra, 2001). Organizations are unlikely to use SaaS unless and until the appropriate employees are in place (Yang et al., 2015). Senyo et al. (2018) recommended that there is still insufficient research directed on SaaS with utilizing the appropriate theories, research model and research methodology and further in depth research are required to enrich the understanding of this issue (Oliveira et al. 2019). Sabi et al. (2016) in educational institutions, the usage of SaaS collaboration solutions has not been comprehensively studied. Furthermore, Lopez-Nicolas et al. (2008) remarked that TAM is suitably used in an organizational perspective, rather than in an individual consumer perspective. Hossain and de Silva (2009) recommended that most studies have applied TAM in physical environments but there is limited research conducted on TAM into virtual environments, modern and complex technology. In particularly, exploring the importance level of adoption factors in the gender perspective and their relationships have been greatly neglected. This study looks at the key factors that distinguish their psychological propensity to adopt SaaS innovations across the genders.

\section{Literature Review and Theoretical Framework}

\subsection{Theoretical Foundation}

Technology Acceptance Model (TAM) model was initially developed to overcome the limitations of Theory of Reasoned Action (TRA) in 1986 by Davis. It is primarily used to study the behavioral intentions of individuals to use technology. TAM suggested that perceived ease of use and the perceived usefulness of technology are predictors of the user's attitude towards the use of technology, subsequent behavioral intentions, and actual use. TAM has a significant impact on the acceptance of new technology (Venkatesh \& Bala, 2010). Lee, Li, Yen, and Huang (2010), established that TAM helps an organization to understand the influence of external variables on the causal link among perceived usefulness, perceived ease of use, and adoption intention. This assists the organization in the execution of any technology. Wu (2011) tested an improved form of TAM and measured the behavior of managers to adoption of SaaS. Du et al. (2013) is used the extended of TAM to examine the acceptance of SaaS by Chinese companies 


\section{International Journal of Economics, Business and Management Research}

Vol. 6, No.02; 2022

ISSN: $2456-7760$

and find that the usefulness, social influence and quality of electronic services as key factors in implementation of SaaS.

\section{1. a. Perceived Usefulness}

According to the TAM, perceived usefulness is a criterion that is frequently considered throughout the adoption process of an information system and is refers to as "the degree to which a person believes that using a particular system would improve their work performance" (Davis, 1986). Numerous empirical studies on the usage of information technology have exposed that the perceived usefulness have a significant effect on the users' intentions (Barakat \& Hussainey, 2013; Featherman \& Pavlou, 2003; Hong \& Zhu, 2006). W.-W. Wu (2011) suggested that adoption of SaaS significantly affected by perceived ease of use and perceived usefulness.

\section{1. b. Perceived Ease of Use}

Another significant aspect in TAM is perceived ease of use, which is the level of effort needed in utilizing a certain system (Davis, 1986). Taylor et al. (1995) integrated and compared the three theories (technology acceptance model, theory of planned behavior and theory of reasoned action) in the context of computer resource center usages and exposed that perceived ease-of-use positively correlated with perceived usefulness. PEOU refers to the degree to which individuals believe that utilizing SaaS is simple to access, learn, and use (Wu, 2011). Several studies have revealed that PEOU can have an effect on both PU and BI (Lopez-Nicolas et al., 2008; Venkatesh \& Bala, 2008; Venkatesh \& Davis, 1996).

\section{1. c. Attitudes}

The term "attitude" refers to the user's subjective assessment or personal affinity towards something and behavioral intention is defined as the strength of the intent to carry out a particular action (Zhao, 2010). According to Technology Acceptance Model - positive attitude towards the innovative technology was the starting point for the intent to adopt it (Gupta \& Arora, 2017). The usual TAM assumes that there is a significant positive relationship between consumers' views about a technology and their adoption intentions, which has been well proven in banking research (Aboelmaged \& Gebba, 2013; Hsu et al., 2011). Attitudes refer to an individual's level of interest in learning about $\mathrm{SaaS}$ and their willingness to test out new technologies and services (Wu, 2011). According to Lopez-Nicolas et al. (2008), attitudes can have an impact on PU and BI. Chan \& Chong (2013) suggested that there is systematic sequences have to follow for adopting any innovation. The subsequent step is adoption of SaaS, which denotes to make decision concerning SaaS (Chong \& Chan, 2012).

\subsection{Factors influencing Adoption intention of SaaS and role of gender}

Research shows that males are more likely to be driven by Perceived Usefulness in terms of behavior intention, (Gefen \& Straub, 1997; Sun \& Zhang, 2006; Venkatesh \& Morris, 2000) whereas women are more impacted by Perceived Ease of Use (Ong \& Lai, 2006). People who are women should pay more attention to PEOU because men are more used to technology than women (Kim, 2010; Ong \& Lai, 2006; Venkatesh et al., 2003). Compared to males, women will see a greater impact of PEOU on behavioral intention and PU. Other research, found the exact reverse or no dissimilarities between the two genders (Cheung, Lee, \& Chen, 2002; Yuen \& Ma, 
2002). The use of technology is exposed to be more appropriate for males than females (Broos, 2005). Furthermore, earlier research has shown that gender has a modest influence on PU. That is, PU will have a greater impact on BI in males than in women (Ong \& Lai, 2006; Venkatesh \& Morris, 2000). PEOU and PU have substantial influence on behavioral intention of information system stronger for females than males. As well as for males, perceived ease of use has a stronger effect on perceived usefulness than for females (Yuen \& Ma, 2002).

The model suggested in this study is founded from previous research, and the research framework was made by modifying items borrowing from the technological \& software-asservices (SaaS) research which is shown in the following figure.

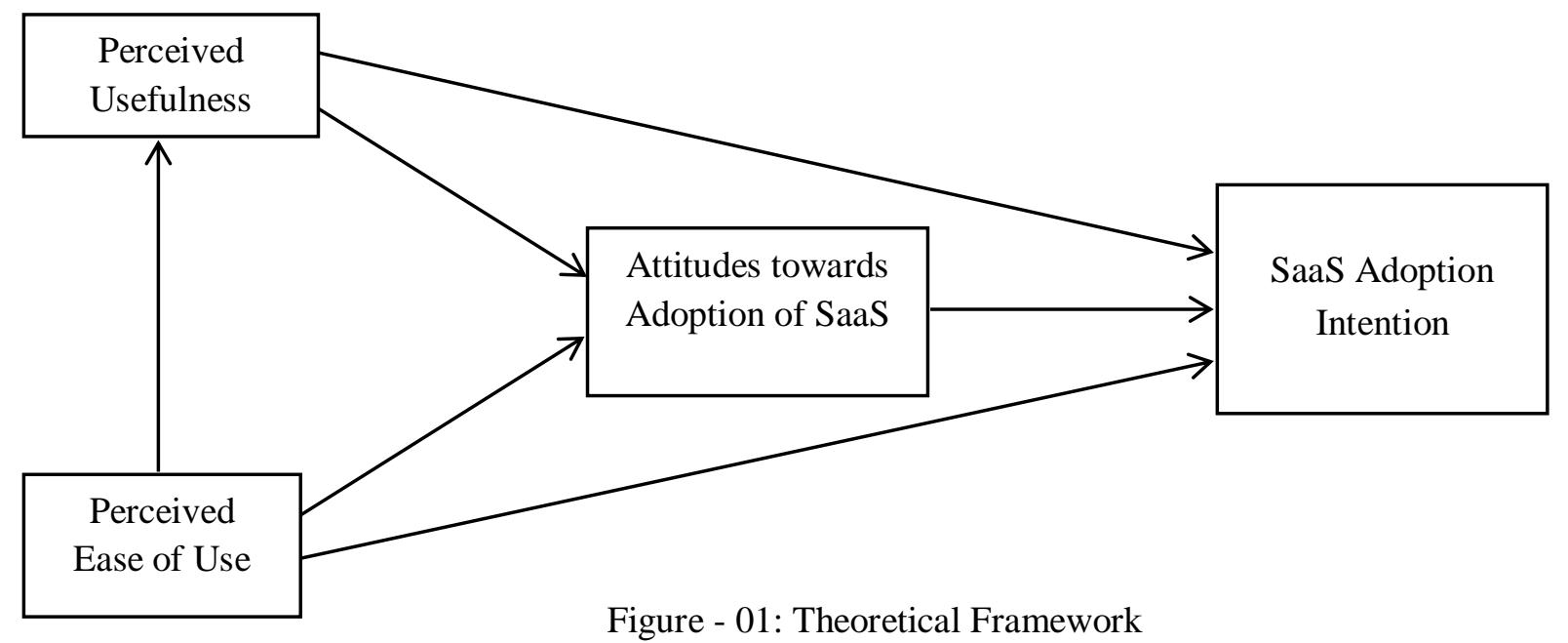

Therefore, based on the Technology Acceptance Model (IAM), there may be significant differences between the male and female employees for the effects of antecedent factors on SaaS Adoption intention. Thus:

H1: The influence of perceived ease of use on perceived usefulness differs significantly between male and female.

$\mathrm{H} 2$ : There is a significant difference for the effect of perceived ease of use on attitudes between male and female

H3: There is a significant difference for the effect of perceived ease of use on Adoption intention between male and female

H4: There is a significant difference for the effect of perceived usefulness on attitudes between male and female

H5: There is a significant difference for the effect of perceived usefulness on Adoption intention between male and female

H6: There is a significant difference for the effect of attitudes on Adoption intention between male and female 


\section{International Journal of Economics, Business and Management Research}

Vol. 6, No.02; 2022

ISSN: $2456-7760$

\section{Method}

\subsection{Data collection \& Sample Size}

Data were collected from all permanent employees of different sister concern of Daffodil Family. The effect size was set at 0.15 (moderate effect), $\alpha$ at 0.05 , and power at 0.80 in the $\mathrm{G}^{*}$ power calculator's input settings. For social and business science research, this is the most commonly suggested set-up (Hair et al., 2017). According to $G^{*}$ power, in this study a minimum sample size of 92 is required to make the study model statistically significant. A structured questionnaire was prepared using Google form that comprise with a set of close-ended questions and link was shared through e-mail, a total of 750 permanent employees of Daffodil Family. A total of 235 employees fill-up the Google form i.e. response rate was 31.33\%. There are two parts in the questionnaire. The first section covered demographic information, whereas the second section included items for measuring the constructs of our study model.

\subsection{Research Instrument}

The measures used to operationalize the constructs involved in the examined models and the questionnaires were mostly adopted from earlier studies, with slight wording modifications. The components or Items for PU and PEOU, and INT have been adopted from Davis (1989). Items for attitude were borrowed from Taylor and Todd (1995). 5-point Likert scales were used for measuring the all items.

\subsection{Data analysis methods}

The associations between the variables were checked using SEM with the SmartPLS3.0, and the data were analyzed using descriptive statistical analysis with the software SPSS version 20.0. The relevance of the path was tested using the bootstrap technique (500 resamples) (Hair et al., 2014).

\section{Analysis and Results}

\subsection{Demographic profile of the respondents:}

A total of 235 completed questionnaires were used in this study's analysis. Table 1 summarizes the demographic profile of respondents. Majority of the respondents (i.e. 54.47\%) were faculty members, while the remaining $45.53 \%$ of the sample were administrative personnel. Majority of the respondents $(53.19 \%)$ are aged less 35 years.

Table 1 Demographic features of respondents $(\mathrm{N}=235)$

\begin{tabular}{|l|l|l|l|}
\hline Characteristic & & Frequency & Percentage (\%) \\
\hline \multirow{3}{*}{ Gender } & Male & 152 & $64.68 \%$ \\
\cline { 2 - 4 } & Female & 83 & $35.32 \%$ \\
\hline \multirow{5}{*}{ Age } & $15-24$ & 19 & $8.08 \%$ \\
\cline { 2 - 4 } & $25-34$ & 106 & $45.11 \%$ \\
\cline { 2 - 4 } & $35-44$ & 72 & $30.64 \%$ \\
\cline { 2 - 4 } & $45-55$ & 29 & $12.34 \%$ \\
\cline { 2 - 4 } & Above 55 & 9 & $3.83 \%$ \\
\hline \multirow{2}{*}{ Department } & Faculty & 128 & $54.47 \%$ \\
\cline { 2 - 4 } & Administrative & 107 & $45.53 \%$ \\
\hline
\end{tabular}




\section{International Journal of Economics, Business and Management Research}

Vol. 6, No.02; 2022

ISSN: $2456-7760$

\subsection{Assessment of Measurement Model:}

PLS-SEM was employed to measure both the measurement and structural models as the framework is relatively complex, composed of both reflective and composite constructs (Hair et al. 2017).

Table 2 Results of measurement model

\begin{tabular}{|c|c|c|c|c|c|c|}
\hline \multirow[t]{2}{*}{ Constructs/Associated Items } & \multicolumn{2}{|c|}{ Loading } & \multicolumn{2}{|l|}{$\mathbf{C R}$} & \multicolumn{2}{|l|}{ AVE } \\
\hline & Male & Female & Male & Female & Male & Female \\
\hline \multicolumn{3}{|l|}{ Perceived Ease of Use (PEOU) } & 0.878 & 0.811 & 0.708 & 0.590 \\
\hline $\begin{array}{l}\text { I think the operation interface of SaaS } \\
\text { is understandable. }\end{array}$ & 0.755 & 0.721 & & & & \\
\hline I think Saas is very user friendly. & 0.875 & 0.755 & & & & \\
\hline $\begin{array}{l}\text { The use of SaaS requires a lot of } \\
\text { mental effort. }\end{array}$ & 0.888 & 0.824 & & & & \\
\hline \multicolumn{3}{|l|}{ Perceived Usefulness (PU) } & 0.837 & 0.838 & 0.633 & 0.633 \\
\hline $\begin{array}{l}\text { The use of SaaS services improves the } \\
\text { quality of operations. }\end{array}$ & 0.826 & 0.806 & & & & \\
\hline SaaS platform can improve efficiency. & 0.833 & 0.781 & & & & \\
\hline SaaS saves time and effort. & 0.722 & 0.80 & & & & \\
\hline \multicolumn{3}{|l|}{ Attitudes Towards Adoption of SaaS } & 0.887 & 0.790 & 0.704 & 0.556 \\
\hline $\begin{array}{l}\text { I believe using SaaS platform is a } \\
\text { good idea. }\end{array}$ & 0.806 & 0.711 & & & & \\
\hline $\begin{array}{l}\text { Using SaaS platform is an enjoyable } \\
\text { experience. }\end{array}$ & 0.840 & 0.778 & & & & \\
\hline I am interested in SaaS platform. & 0.871 & 0.748 & & & & \\
\hline \multicolumn{3}{|l|}{ Intention to Adopt } & 0.763 & 0.796 & 0.523 & 0.568 \\
\hline I have used SaaS services & 0.573 & 0.628 & & & & \\
\hline $\begin{array}{l}\text { I am willing to continue using the } \\
\text { SaaS. }\end{array}$ & 0.730 & 0.775 & & & & \\
\hline $\begin{array}{l}\text { I will recommend SaaS services to my } \\
\text { friends. }\end{array}$ & 0.842 & 0.843 & & & & \\
\hline
\end{tabular}

The convergent validity and discriminant validity were used to assess the measurement model. As suggested by Hair et al. (2014), factor loading, average variances extract (AVE) and composite reliability (CR) are to be considered in determining convergent validity. To assess indicator reliability, the loading of the associated items for each construct should be checked and the loadings must be greater than 0.7 (Hair et al., 2017). If CR and AVE exceed the threshold, a loading of 0.4 to 0.7 is considered acceptable (Hair et al., 2017). Table 2, shows the results of measurement model that indicate the composite reliability (CR) and average variance extracted (AVE) is higher than 0.7 and 0.5 respectively, showing the acceptable reliability and convergent validity for both gender groups. Based on the results of initial measurement model, two (2) items were dropped due to poor factor loading, remaining total 14 items for the final analysis (Table 2). Moreover, we checked the discriminant validity for female and male employees using the 


\section{International Journal of Economics, Business and Management Research}

Vol. 6, No.02; 2022

ISSN: $2456-7760$

Fornell-Larcker criterion and heterotrait-monotrait (HTMT) approach (Henseler et al., 2015). Therefore, both the Fornell-Larcker criterion and HTMT 0.85 demonstrate acceptable discriminant validity for both groups.

\subsection{Structural Model Assessment and Multi-group Analysis:}

For assessing the structural model $\mathrm{R}^{2}$, standard beta, $\mathrm{t}$-values through a bootstrapping process with a resample of 5,000, and the effect sizes $\left(\mathrm{f}^{2}\right)$ were examined as recommended by Hair et al. (2017). Multi-collinearity was assessed via variance inflation factors (VIF) and significance of path coefficient.

Table 3 hypothesis testing results

\begin{tabular}{|c|l|c|c|c|c|c|c|c|c|}
\hline \multirow{2}{*}{ Hypothesis } & \multirow{2}{*}{} & & \multicolumn{2}{|c|}{$\begin{array}{c}\text { Path } \\
\text { Coefficients }\end{array}$} & \multicolumn{2}{c|}{ t-value } & \multicolumn{2}{c|}{ P-value difference } & \multicolumn{2}{c|}{ Supported } \\
\cline { 3 - 10 } & & Male & Female & Male & Female & $\begin{array}{c}\text { Henseler's } \\
\text { MGA }\end{array}$ & $\begin{array}{c}\text { Permutation } \\
\text { test }\end{array}$ & Male & Female \\
\hline H1 & PEOU -> PU & 0.424 & 0.305 & 4.554 & 2.173 & 0.986 & 0.021 & Yes & Yes \\
\hline H2 & PEOU -> ATT & 0.256 & 0.053 & 1.881 & 0.317 & 0.357 & 0.612 & No & No \\
\hline H3 & PEOU -> INT & 0.093 & -0.158 & 1.007 & 1.108 & 0.129 & 0.564 & No & No \\
\hline H4 & PU -> ATT & 0.287 & 0.363 & 2.167 & 3.443 & 0.961 & 0.042 & Yes & Yes \\
\hline H5 & ATT -> INT & 0.370 & 0.352 & 4.361 & 2.747 & 0.971 & 0.030 & Yes & Yes \\
\hline H6 & PU -> INT & 0.318 & 0.296 & 4.225 & 2.127 & 0.964 & 0.036 & Yes & Yes \\
\hline
\end{tabular}

Note - 01: Henseler's MGA technique, $\mathrm{p}$ value lower than $5 \%$ or higher than $95 \%$ shows significant differences between specific paths at the 5\% level. Note - 02: ATT- Attitudes, INT Intentions, PEOU - Perceived Ease of Use, PU - Perceived Usefulness

The results for both female and male employees showed that (see table 3) VIF were < 3.30 with significance value of all underlying items. This study has developed a total of six hypotheses. The statistical results presented that four hypotheses were accepted (see table 3). Measurement invariance must be tested prior to comparing the path coefficient between two groups (i.e. male and female employees), using Multi-group Analysis (MGA) to test the proposed hypotheses (Henseler et al., 2016). The measurement invariance of composites approach (MICOM) was employed, as per current literature (Henseler et al., 2016). MICOM contains three steps: (a) configural invariance assessment (b) compositional invariance assessment (c) composite equality i.e the assessment of equal means and variances (Rasoolimanesh et al., 2017). Using MICOM, partial measurement invariance was established via configural and compositional invariance; a requirement for MGA (Rasoolimanesh et al., 2019). Further, MICOM demonstrated equal means for constructs (Perceived ease of use, perceived usefulness, and attitudes towards SaaS) alongside, SaaS adoption intentions, for both male and female groups of employees. 


\section{International Journal of Economics, Business and Management Research}

Vol. 6, No.02; 2022

ISSN: $2456-7760$

\subsection{Results of Multi-Group Analysis (MGA):}

Multi-group analysis (MGA) aids researchers to measure whether two or more variables have the same/diverse relation across groups (MacKinnon, 2011). Specifically, when the moderator variable is categorical, such as Gender (male \& female group), faculty and administrative group, nationalities or industry types, the suitable analysis technique would be MGA if the moderation effect is on the whole model. In other words, test and compare the effect of each structural path on different groups (Aguinis et al., 2017; Ting, Fam, Hwa, Richard, \& Xing, 2019). Tables 3 illustrate the results of proposition testing and MGA for both gender groups. Two nonparametric approaches were applied to test the proposed hypotheses: one is Henseler's MGA (Henseler et al., 2009) and another one is the permutation test (Chin \& Dibbern, 2010). This facilitated the comparison of the effect of perceived ease of use, perceived usefulness, attitudes and Adoption intention of SaaS between male and female employees. Conversely, the findings do not underpin the effect of perceived ease of use on attitudes and behavioral intention to Adoption of SaaS for both groups $(\mathrm{H} 2, \& \mathrm{H} 3)$. Further, MGA results identified that perceived ease of use has a positive influence on perceived usefulness for both male and female employees (H1). However, as the results shown perceived usefulness have positive stimulus to form attitudes towards SaaS and intention to SaaS for both gender groups (H4, H6). The findings suggest that attitudes towards SaaS have positive effect on intention to use SaaS between two gender groups of employees (H5).

\subsection{Results of Importance-Performance Matrix Analysis (IPMA):}

The quadrants were drawn using the average of performance and average of importance from the IPMA results. Ringle and Sarstedt (2016) suggested that IPA supports the interpretation of PLSSEM results through generating Importance-Performance Map Analysis (IPMA) illustrated in figure 02 . The performance of elements' is represented by the vertical axis, which ranges from bad performance to excellent performance. The horizontal line denotes the perceived importance of the elements, ranging between least important to most important. In this study, IPMA was used to detect the importance and performance of perceived ease of use, perceived usefulness and attitudes towards SaaS in forming behavioral intentions of male \& female employees towards SaaS. Figure 02 shows the IPMA results for both gender groups. Accordingly, perceived usefulness was identified as the most important and performing constructs for both gender groups of employees but its performance is higher for female employees. Further, the importance of attitudes antecedent factor is high but performance is lower for female and for male importance - performance is low. Finally, the importance of Perceived ease of use is high but performance is low for male employees. On the hand, for female group performance is high but importance is very low. 


\section{International Journal of Economics, Business and Management Research}

Vol. 6, No.02; 2022

ISSN: $2456-7760$

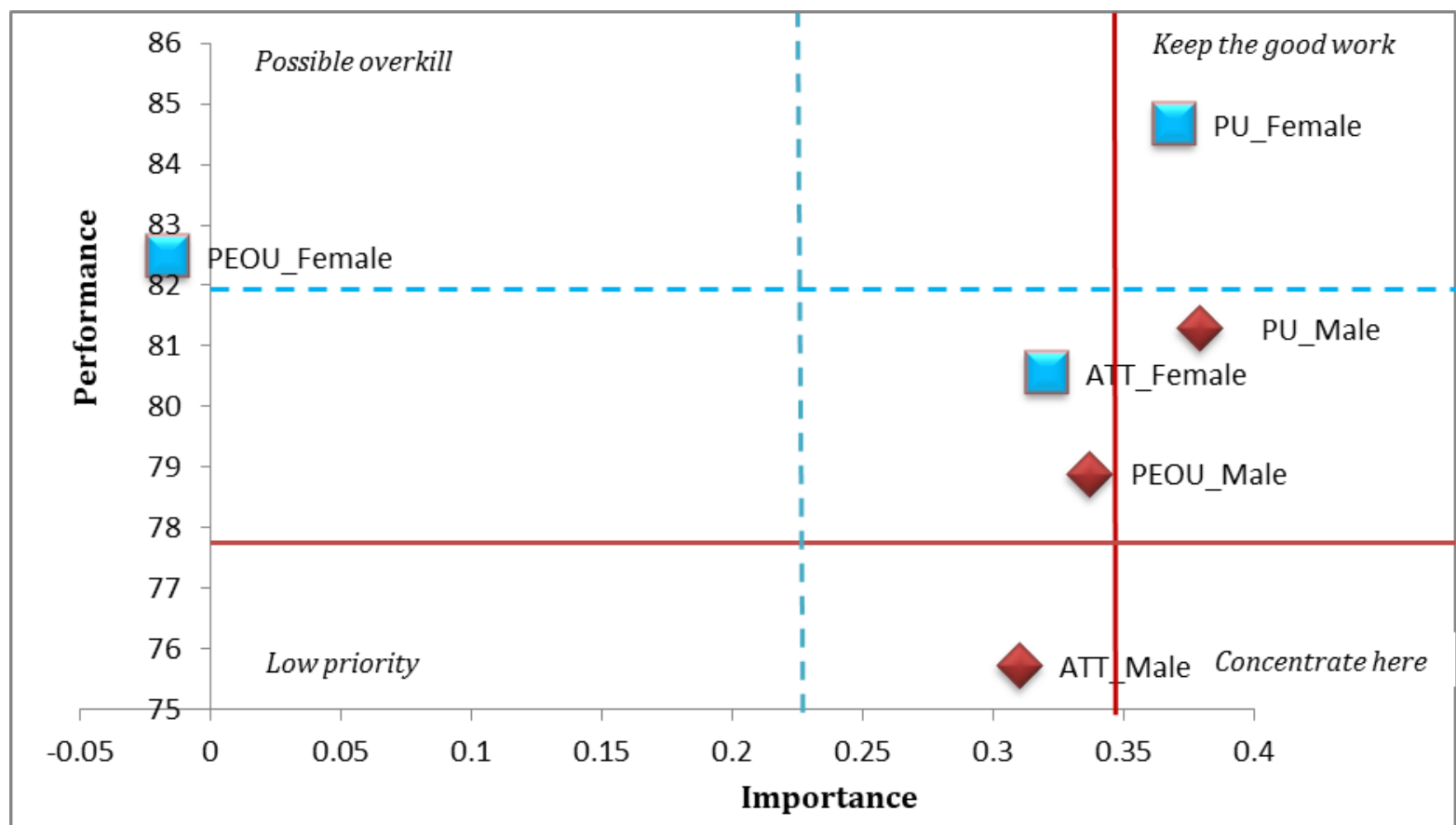

Figure 02: Gender based Importance Performance Matrix Analysis (IPMA)

Table 4: Categorization of INT factors in IPA quadrant

\begin{tabular}{lll}
\hline INT factor & IPA quadrant & \\
\cline { 2 - 3 } & Male & Female \\
\hline ATT & Low priority & Concentrate here \\
\hline PEOU & Concentrate here & Possible overkill \\
\hline PU & Keep the good work & Keep the good work \\
\hline
\end{tabular}

\section{Discussion and Conclusion}

The study investigated whether the intentions of employees toward Adoption of SaaS differ across gender by examining the effects of influencing factors. There are significant disparities in the influence of perceived ease of use and perceived usefulness between male \& female employees and attitudes on their Adoption intention SaaS, were hypothesized, and underpinned by Technology Acceptance Model (TAM). The results did not support H2 \& H3, suggesting that perceived ease of use has no significant effect on attitudes towards SaaS and intention to adopt SaaS across the both gender groups. The effects of perceived usefulness and attitudes towards SaaS were high for male and female employees. Additionally, IPA results shows perceived usefulness holds the highest performance among all antecedents for both male and female employees, while the level of importance is higher for male employees. However, perceived ease of use is identified as the second most important antecedents for male employees conversely its performance is below average. However, importance of this construct is very low for female group of employees. As such, the results recommend that easiness has not influence the female employees towards Adoption of SaaS system. The study was limited to employees of one 


\section{International Journal of Economics, Business and Management Research}

Vol. 6, No.02; 2022

ISSN: $2456-7760$

organization and employees using this system around one year. In order to overcome this drawback, the future study should be conducted comparative research across different types of organizations and users (like, early Adopter, early majority and late majority etc.). Even so, this study extends various managerial implications for management to smooth the functioning of SaaS system. The MGA and IPA results exhibit that perceived usefulness has the highest effect and important on both male and female employees positive intentions towards SaaS. This variable should be considered and keep it long-term for the betterment of automation process of organization. However, the management must focus on improving the perceived ease of use for female in order to improve their intentions of and support for adopt SaaS system more generally. Also, authority gives more effort to reform the attitudes of male employees.

\section{References:}

Aguinis, H., Edwards, J. R., \& Bradley, K. J. (2017). Improving Our Understanding of Moderation and Mediation in Strategic Management Research. Organizational Research Methods, 20(4), 665-685.

Benlian, A., \& Hess, T. (2011). Opportunities and risks of software-as-a-service: Findings from a survey of IT executives. Decision Support Systems, 52(1), 232-246.

Broos, A. (2005). Gender and information and communication technologies (IT) anxiety: Male self-assurance and female hesitation. Cyber Psychology \& Behaviour, 8 (1), 21-31.

Boyd, B. K., Haynes, K. T., Hitt, M. A., Bergh, D. D., \& Ketchen, D. J. (2012). Contingency hypotheses in strategic management research: Use, disuse, or misuse. Journal of Management, 38(1), 278-313.

Chan, F. T., \& Chong, A. Y.-L. (2013). Determinants of mobile supply chain management system diffusion: a structural equation analysis of manufacturing firms. International Journal of Production Research, 51(4), 1196-1213.

Cheung, C. M. K., Lee, M. K. O., \& Chen, Z. (2002). Using the Internet as a learning medium: An exploration of gender difference in the adoption of FaBWeb. In Proceedings of the 35th Hawaii international conference on system sciences (Held at Hawaii on 7-10 January 2002).

Davis, F.D. (1989). Perceived Usefulness, Perceived Ease of Use, and User Acceptance of Information Technology, MIS Quarterly, 13(3). pp. 319-340

Davis, F. D., Bagozzi, R. P., \& Warshaw P. R. (1989). User Acceptance of Computer Technology: A Comparison of Two Theoretical Models. Management Science 35, 9821003.

Du, J., Lu, J., Wu, D., Li, H., \& Li, J. (2013). User acceptance of software as a service: Evidence from customers of China's leading e-commerce company, Alibaba. Journal of Systems and Software, 86(8), 2034-2044. https://doi.org/10.1016/j.jss.2013.03.012.

Gefen, D., \& Straub, D. W. (1997). Gender differences in the perception and use of email: An extension to the technology acceptance model. MIS Quarterly, 21(4), 389-400. 


\section{International Journal of Economics, Business and Management Research}

Vol. 6, No.02; 2022

ISSN: $2456-7760$

Hair, J.F., Sarstedt, M., Hopkins, L. and Kuppelwieser, V.G. (2014) 'Partial least squares structural equation modeling (PLS-SEM): an emerging tool in business research', European Business Review, 26(2), pp.106-121.

Hair, J. F., Hult, G. T. M., Ringle, C. M., \& Sarstedt, M. (2017). A primer on partial least squares structural equation modeling (PLS-SEM) (2nd ed.). Thousand Oaks, CA: Sage.

Henseler, J., Ringle, C. M., \& Sarstedt, M. (2015). A new criterion for assessing discriminant validity in variance based structural equation modeling. Journal of the Academy of Marketing Science, 43(1), 115-135. doi:10.1007/s11747-014-0403-8

Klein, K.J., Conn, A.B.,\& Sora,J.S.(2001). Implementing computerized technology: An organizational analysis. Journal of Applied Psychology, 86 (5), 811-824.

Kim, Y.-M. (2010). Gender role and the use of university library website resources: A social cognitive theory perspective. Journal of Information Science, 36(5), 603-617.

Lee, Y. C., Li, M. L., Yen, T. M., \& Huang, T. H. (2010). Analysis of adopting an integrated decision making trial and evaluation laboratory on a technology acceptance model. Expert Systems with Applications, 37(2), 1745-1754.

Lopez-Nicolas, C., Molina-Castillo, F. J., \& Bouwman, H. (2008). An assessment of advanced mobile services acceptance: Contributions from TAM and diffusion theory models. Information \& Management, 45(6), 359-364.

MacKinnon, D. P. (2011). Integrating Mediators and Moderators in Research Design. Research on Social Work Practice, 21(6), 675-681.

Ong, C., \& Lai, J. (2006). Gender differences in perceptions and relationships among dominants of e-learning acceptance. Computers in Human Behaviour, 22(5), 816-829.

Oliveira, T., Martins, R., Sarker, S., Thomas, M., \& Popovič, A. (2019). Understanding SaaS adoption: The moderating impact of the environment context. International Journal of Information Management, 49, 1- 12. https://doi.org/10.1016/j.ijinfomgt.2019.02.009.

Sun, H., \& Zhang, P. (2006). The role of moderating factors in user technology acceptance. International Journal of Human Computer Studies, 64(2), 53-78.

Sabi, H. M., Uzoka, F.-M. E., Langmia, K., \& Njeh, F. N. (2016). Conceptualizing a model for adoption of cloud computing in education. International Journal of Information Management, 36(2), 183-191. https://doi.org/10.1016/j.ijinfomgt.2015.11.010.

Senyo, P. K., Addae, E., \& Boateng, R. (2018). Cloud computing research: A review of research themes, frameworks, methods and future research directions. International Journal of Information Management, 38(1), 128-139.

Ting, H., Fam, K. S., Hwa, J. C. J., Richard, J. E., \& Xing, N. (2019). Ethnic food consumption intention at the touring destination: The national and regional perspectives using multigroup analysis. Tourism Management, 71, 518-529.

Tornatzky, L. G., \& Fleischer, M. (1990). The Processes of Technological Innovation. Lexington: Lexington Books 


\section{International Journal of Economics, Business and Management Research}

Vol. 6, No.02; 2022

ISSN: $2456-7760$

Tan, X., \& Kim, Y. (2015). User acceptance of SaaS-based collaboration tools: A case of Google docs. Journal of Enterprise Information Management, 28(3), 423-442. https://doi.org/10.1108/jeim-04-2014-0039.

Taylor, S., \& Todd, P. A. (1995b). Understanding information technology usage: a test of competing models. Information System Research, 6(2), 144-174.

Venkatesh, V.; Bala, H. (2010). Technology Acceptance Model 3 and a Research Agenda on Interventions. Decis. Sci.39, 273-315.

Venkatesh, V., \& Bala, H. (2008). Technology acceptance model 3 and a research agenda on interventions. Decision Sciences, 39(2), 273-315.

Venkatesh, V., \& Davis, F. D. (1996). A model of the antecedents of perceived ease of use: Development and test. Decision Sciences, 27(3), 451-481.

Venkatesh, V., \& Davis, F. D. (2000). A theoretical extension of the technology acceptance model: Four longitudinal field studies. Management Science, 46(2), 186-204.

Venkatesh, V., \& Morris, M. (2000). Why don't men ever stop to ask for direction? Gender, social influence, and their role in technology acceptance and usage behavior. MIS Quarterly, 24(1), 115-139

Venkatesh, V., Morris, M. G., Davis, G. B., \& Davis, F. D. (2003). User acceptance of information technology: Toward a unified view. MIS Quarterly, 27(3), 425-478.

Wease, G., Boateng, K., Yu, C.-J., Chan, L., \& Barham, H. (2018). Technology assessment: Cloud service adoption decision. In T. U. Daim, L. Chan, \& J. Estep (Eds.), Infrastructure and technology management: Contributions from the energy, healthcare and transportation sectors (pp. 447-471). Cham: Springer International Publishing.

Wu, W.-W. (2011). Developing an explorative model for SaaS adoption. Expert Systems with Applications, 38(12), 15057-15064.

Yuen, A., \& Ma, W. (2002). Gender differences in teacher computer acceptance. Journal of Technology and Teacher Education, 10(3), 365-382. http://www.editlib.org/p/15142

Zorrilla, M., \& García-Saiz, D. (2013). A service oriented architecture to provide data mining services for non-expert data miners. Decision Support Systems, 55(1), 399-411. 